\title{
NUMERICAL STUDY OF EROSION IN CRITICAL COMPONENTS OF SUBSEA PIPELINE: TEES VS BENDS
}

\author{
Hassan Pouraria ${ }^{\mathrm{a}, \mathrm{b}}$, Jung Kwan Seo ${ }^{\mathrm{a}, \mathrm{b},{ }^{*}}$, Jeom Kee Paik ${ }^{\mathrm{a}, \mathrm{b}, \mathrm{c}}$ \\ ${ }^{a}$ Department of Naval Architecture and Ocean Engineering, Pusan National University, Busan 609-735, Republic of Korea \\ ${ }^{\mathrm{b}}$ The Korea Ship and Offshore Research Institute (The Lloyd's Register Foundation Research Centre of Excellence), \\ Pusan National University, Busan 609-735, Republic of Korea \\ ${ }^{\mathrm{c}}$ Department of Mechanical Engineering, University College London, Torrington Place, London WC1E 7JE, UK
}

Elbows are a vulnerable part of piping systems in erosive environments. Traditionally, plugged tees are used instead of elbows when the erosion rate is high. However, the advantage of plugged tees over elbows in large-scale pipelines is unclear. A comprehensive computational fluid dynamics study was carried out to predict the erosion rate in plugged tees and elbows. A numerical method was first used for aluminium elbows and tees with available experimental data through which the accuracy of the numerical solution was verified. After validating the model, numerical modelling was used to compare the erosion rates of plugged tees and elbows in varying geometrical conditions, ranging from 0.0254-0.6 m diameter carbon steel pipes transmitting multiphase gas/sand flow. The effects of internal flow velocity and sand particle size on erosion rates were also investigated. The numerical results revealed that the erosion ratio between plugged tees and elbows strongly depends on the internal diameter of the pipe, the flow velocity and particle size. Hence, the influence of these parameters should be considered for proper selection of the fittings to be used. Finally, numerical modelling of erosion in two subsea jumpers outfitted with standard elbows and plugged tees was presented.

Keywords: Numerical Modelling; CFD; Erosion; Subsea Pipeline; Elbow

\section{INTRODUCTION}

Sand production is a common occurrence in offshore oil and gas production systems. Damage from erosion due to particulate gas/sand flow in piping systems causes significant financial and environmental problems in the petroleum and several other industries. To avoid environmental issues and unscheduled shutdowns of production, it is of the utmost importance to predict such damage. Although sand is always produced during oil and gas production, the amount produced is not significant in the early stage of production. However, in late stages during which the pressure of the reservoir falls below 6.9 $\mathrm{MPa}$, a significant increase in sand production is inevitable, which in turn introduces an important challenge to damage prediction and mitigation. Of note, due to the low pressure of reservoirs in the late stage, it is not usually desirable to install sand exclusion systems because they can potentially decrease the production rate (Salama 2000a, 2000b, 2000c; Parsi et al. 2014).

Computational fluid dynamics (CFD) is the most comprehensive approach for predicting the vulnerable spots in piping systems and estimating the associated damage from erosion. CFD models can also be used to minimise such damages by optimising the geometry and flow conditions (Parsi et al. 2014; Barton 2003; Lee et al. 2014) of the system.

The elbows in a flow transmission system are exposed to sand erosion damage. A common belief in the industry holds that plugged tees are more robust than standard elbows with respect to erosion damage in gas/sand flows. Hence, plugged tees are usually used instead of standard elbows when significant erosion is expected (Chen et al. 2006).

Because of the broad application of elbows in the industry, many researchers have studied their performance in gas/sand and liquid/sand flows. Several experimental, analytical and numerical studies on erosion in elbows have been published (Abdolkarimi and Mohammadikhah 2013; Safaei et al. 2014, Pereira et al. 2014), and a comprehensive review can be found in Parsi et al. (2014). However, only a few researchers have studied the behaviour of plugged tees in an erosive environment (Chen et al. 2004; Bourgoyne 1989; Parslow et al. 1997).

Bourgoyne (1989) experimentally compared the erosion in elbows and plugged tees under high sand loading conditions and observed that plugged tees were considerably less subject to erosion damage than elbows. Edwards et al. (2001) used an Eulerian-Lagrangian approach to model erosion in a small-diameter elbow and plugged tee and observed that, under identical 
conditions, the erosion rate in the plugged tee was much lower than that in the standard elbow. Brown (2002) used a EulerianEulerian model to investigate the erosion in a tee junction. However, due to the inherent disability of such models in tracking particles and providing data on impingement, he could not model the erosion rate. Chen et al. (2006) performed experimental and numerical studies to compare the performance of aluminium plugged tees and elbows in an erosive environment, and found that the erosion rate in plugged tees was less than that in elbows. Their numerical results indicated that as the internal diameter of fittings increases, the erosion rate in tees may become important. However, their study was limited to pipelines with internal diameters less than $0.2 \mathrm{~m}$. Moreover, due to the different behaviour of aluminium and carbon steel in an erosive environment, the results cannot be applied to commonly used steel pipelines. Pontaza et al. (2013) numerically studied the erosion in the large-scale elbows and plugged tees used in subsea jumpers and found that using an elbow in large-scale pipes resulted in better performance than that of plugged tees. However, data on the size of the particles and pipes were not reported in their work. Azimian and Bart (2014) reported that in contrast to gas/solid flow, the resistance of a plugged tee in liquid/solid flow is less than that of an elbow with respect to erosion.

The numerical studies of the relative erosion occurring in plugged tees and elbows in small- and large-scale pipes have provided contradictory results. Although the proper selection of fittings is an important issue, in terms of the state of the art, there is no comprehensive study of relative erosion between plugged tees and elbows that spans the common operating conditions ranging from small to large pipe diameters or with different sand particle sizes and flow rates. This study aimed to fill this gap. To this end, a CFD-based erosion model was developed for comparative study of the erosion rate in standard elbows and plugged tees.

A numerical method was first used for an elbow and plugged tee with available experimental data to verify the accuracy of the numerical solution. Then, numerical modelling was used for comparative study of the erosion rates in plugged tees and elbows over a wide variety of geometrical conditions, ranging from 0.0254-0.6 m diameter carbon steel (AISI 4130) pipes transmitting multiphase gas/sand flows. Furthermore, the effects of sand particle size and internal flow velocity on the erosion ratio between plugged tees and elbows was investigated. Finally, numerical simulations were performed for two subsea jumpers outfitted with elbows and plugged tees to evaluate their performance in an erosive environment.

\section{NUMERICAL MODEL}

The erosion predictions were calculated by CFD using Eulerian-Lagrangian approach. Modelling erosion with this approach is a three-step process. The first step is to model the turbulent flow field using Eulerian model. In the second step, particle tracking is performed using a Lagrangian approach. The particle trajectories are calculated based on the calculated flow-field in the first step and the exchange forces. In the third step, the data provided from the second step are used to calculate the erosion rate at the fitting wall.

\subsection{Eulerian Approach}

The conservation equations for mass and momentum are written as follows:

$$
\begin{aligned}
& \frac{\partial}{\partial x_{i}}\left(\rho u_{i}\right)=0 \\
& \frac{\partial}{\partial x_{j}}\left(\rho u_{i} u_{j}\right)=-\frac{\partial P}{\partial x_{i}}+\frac{\partial}{\partial x_{j}}\left[2 \mu S_{i j}-\frac{2}{3} \mu \delta_{i j} \frac{\partial u_{i}}{\partial x_{i}}\right]+\frac{\partial}{\partial x_{j}}-\left(\rho u_{i}^{\prime} u_{j}^{\prime}\right.
\end{aligned}
$$

where $\delta_{\mathrm{ij}}$ is unit tensor, and mean strain rate $\mathrm{S}$ is defined as follows:

$$
\mathrm{S}_{\mathrm{ij}}=\frac{2}{3}\left(\left(\frac{\partial \mathrm{u}_{\mathrm{i}}}{\partial \mathrm{x}_{\mathrm{j}}}\right)+\left(\frac{\partial \mathrm{u}_{\mathrm{j}}}{\partial \mathrm{x}_{\mathrm{i}}}\right)\right)
$$

To close the system of equations we need to model the terms $-\rho u_{1}^{\prime} u_{1}^{\prime}$ in Equation 2. These terms are called Reynolds stresses. The Boussinesq hypothesis is the most popular method used to model the Reynolds stresses by introducing an eddy viscosity:

$$
-\rho u_{1} u_{j}^{\prime}=2 \mu S_{t}-\frac{2}{3} \mu \delta_{i j}\left(\rho k+\mu_{t} \frac{\partial u_{k}}{\partial x_{k}}\right)
$$

Several turbulence models can be used to calculate the turbulent viscosity $\mu_{\mathrm{t}}$. Two-equation turbulence models are the simplest complete models for investigating turbulent flow because the turbulence velocity and length scale can be 
independently determined by solving two separate transport equations. In this study, the standard k- $\varepsilon$ model was used to consider the turbulent effects.

In the standard k- $\varepsilon$ model, the turbulence kinetic energy and the dissipation rate are obtained from the following transport equations:

$$
\begin{aligned}
& \frac{\partial}{\partial \mathrm{t}}(\rho \mathrm{k})+\frac{\partial}{\partial \mathrm{x}_{\mathrm{i}}}\left(\rho \mathrm{ku}_{\mathrm{i}}\right)=\frac{\partial}{\partial \mathrm{x}_{\mathrm{j}}}\left[\left(\mu+\frac{\mu_{\mathrm{t}}}{\sigma_{\mathrm{k}}}\right) \frac{\partial \mathrm{k}}{\partial \mathrm{x}_{\mathrm{j}}}\right]+\mathrm{G}_{\mathrm{k}+} \mathrm{G}_{\mathrm{b}}-\rho \varepsilon-\mathrm{Y}_{\mathrm{M}} \\
& \frac{\partial}{\partial \mathrm{t}}(\rho \varepsilon)+\frac{\partial}{\partial \mathrm{x}_{\mathrm{i}}}\left(\rho \varepsilon \mathrm{u}_{\mathrm{i}}\right)=\frac{\partial}{\partial \mathrm{x}_{\mathrm{j}}}\left[\left(\mu+\frac{\mu_{\mathrm{t}}}{\sigma_{\varepsilon}}\right) \frac{\partial \varepsilon}{\partial \mathrm{x}_{\mathrm{j}}}\right]+\mathrm{C}_{1 \varepsilon \mathrm{k}} \frac{\varepsilon}{\mathrm{k}}\left(\mathrm{G}_{\mathrm{k}+} \mathrm{C}_{3 \varepsilon} \mathrm{G}_{\mathrm{b}}\right)-\mathrm{C}_{2 \varepsilon} \rho \frac{\varepsilon}{\mathrm{k}}
\end{aligned}
$$

where $G_{k}$ and $G_{b}$ represent the generation of turbulence kinetic energy due to the mean velocity gradients and buoyancy, respectively. $Y_{\mathrm{m}}$ represents the contribution of the fluctuating dilatation in compressible turbulence to the overall dissipation rate.

The turbulent viscosity is computed using the following equation in which $\mathrm{C}_{\mu}$ is a constant.

$$
\mu_{t}=\rho C_{\mu} \frac{k^{2}}{\varepsilon}
$$

The following default constants were used in this study:

$$
\mathrm{C}_{1 \varepsilon}=1.44, \mathrm{C}_{2 \varepsilon}=1.92, \mathrm{C}_{\mu}=0.09, \sigma_{\mathrm{k}}=1.0, \sigma_{\varepsilon}=1.3
$$

Fluent 15 was used to solve the governing equations with the finite volume method.

\subsection{Lagrangian Approach}

In the second step, the particle phase is modelled using a Lagrangian approach in which the trajectory of each particle is calculated by integrating the force balance on the particle. The governing equation of the motion of particles is written as

$$
m_{p} \frac{d u_{p}}{d t}=F_{d}\left(u_{f}-u_{p}\right)+F_{b}+F_{p}+F_{M}
$$

where $p$ and $f$ denote the particle and fluid, respectively. The first term on the right-hand side of the equation represents the drag force, and the other terms represent the buoyancy force, pressure gradient force and virtual mass force, respectively.

The drag force is computed by

$$
F_{d}=\frac{18 \mu}{\rho_{p} d_{p}^{2}} \frac{C_{d} R e}{24}
$$

where $\rho_{\mathrm{p}}, d_{\mathrm{p}}$ denote the density and diameter of a particle, and $\mu$ is the viscosity of the fluid. $R e$ is the relative Reynolds number, which is defined as

$$
R e=\frac{\rho d_{p}\left|u_{p}-u_{f}\right|}{\mu}
$$

The drag coefficient $C_{d}$ for a spherical particle is determined by

$$
C_{d}=a_{1}+\frac{a_{2}}{R e}+\frac{a_{3}}{R e^{2}}
$$

where $a_{1}, a_{2}$ and $a_{3}$ are constants derived from the Morsi-Alexander drag law (Morsi and Alexander 1971).

The buoyancy force is quantified by

$$
F_{b}=\frac{1}{6} \pi d_{p}^{3}\left(\rho_{p}-\rho_{f}\right) g
$$

The pressure gradient is also determined according to

$$
F_{p}=\frac{1}{4} \pi d_{p}^{3} \nabla P
$$

Because of the low density of the continuous phase (gas) compared to that of the dispersed phase (sand particles), the effect of virtual mass force was neglected in this study.

In spite of the low sand loading (low volume fraction of sand) in this study, the volume fraction of sand in specific regions of the flow domain may become high such that the effect of the particles on the flow field becomes important. To consider such effects, a two-way coupling was adopted to model the interactions between the particles and the continuous turbulent flow-field. The stochastic tracking (random walk) model, which considers the effects of instantaneous turbulent velocity fluctuations on the particle trajectories, was used in particle tracking.

\subsection{Erosion Model}


From the above procedures, impingement data such as the speed and the angle of impact of the sand particles are provided as the particles hit the fitting wall. Using this information, the erosion rate can be calculated.

The erosion rate was modelled using the E/CRC erosion model, as follows (Ahlert 1994; McLaury 1996; Njobuenwu and Fairweather 2012; Zhang et al. 2007):

$\mathrm{ER}=A F_{s} V_{p}^{n} f(\theta)$

where ER is the erosion ratio, which is defined as the ratio of the material removal at the wall to the particle mass flow rate. $V_{p}$ is the velocity of the particles, and $A$ is a constant that depends on the material used in the pipe. $F_{s}$ is the particle shape coefficient, which is considered equal to 0.2 for fully rounded particles. $f(\theta)$ is the impact angle function for a gas/solid flow defined as follows:

$$
f(\theta)=\left\{\begin{array}{cc}
K_{1} \theta^{2}+K_{2} \theta & \theta \leq \theta_{0} \\
K_{3} \cos ^{2} \theta \sin \left(K_{4} \theta\right)+K_{5} \sin ^{2} \theta+K_{6} & \theta>\theta_{0}
\end{array}\right.
$$

where $\theta$ is the impact angle of the particles and the constants $K_{i}$ for $\mathrm{i}=1-6$ and $\theta_{0}$ are listed in Table 1 (Wang and Shirazi 2003, Chen et al. 2004, Oka et al. 1997). Figure 1 shows the angle function for the carbon steel used in this study.

As the particles hit the fitting wall, their reflected velocity becomes less than the incoming velocity. Previous studies revealed that the angle of impact has a significant effect on the coefficients of restitution (Grant and Tabakoff 1975; Sommerfeld and Huber 1999)

The respective perpendicular and parallel coefficients of restitution for sand impacting AISI 4130 carbon steel are incorporated into the model according to Forder et al. (1998):

$$
\begin{aligned}
e_{\text {per }}=0.988-0.78 \theta+0.19 \theta^{2}-0.02 \theta^{3}+0.027 \theta^{4} \\
e_{\text {per }}=1-0.78 \theta+0.85 \theta^{2}-0.21 \theta^{3}+0.028 \theta^{4}-0.022 \theta^{5}
\end{aligned}
$$

where $\theta$ is the impact angle of the particles. The impact angle function $\mathrm{f}(\theta)$ and the restitution coefficient $e$ were introduced to the model as a piecewise linear function.

\section{GEOMETRY AND BOUNDARY CONDITIONS}

Numerical simulations were first carried out for a plugged tee and elbow with internal diameters of $0.0254 \mathrm{~m}$. To validate the numerical results, the solution was performed for aluminium-made fittings with available experimental data regarding the erosion ratio between the plugged tee and elbow.

The carrier fluid used in this study was air, and the mass flow rate of the sand particles was specified to be equal to 0.208 $\mathrm{gr} / \mathrm{s}$ at the inlet for $0.0254 \mathrm{~m}$ diameter geometries. The velocity inlet boundary condition was applied at the inlet. The velocity of air at the inlet was $45.72 \mathrm{~m} / \mathrm{s}$, which is compatible with that in the experiment of Chen et al. (2006). The pressure outlet boundary condition with the gauge pressure of zero was imposed at the outlet, and the no-slip boundary condition was applied for wall boundaries. The diameter of the sand particles in the experiment was $250 \mu \mathrm{m}$. In the validation step, the erosion model was modified according to the behaviour of aluminium in an erosive environment. Hence, an appropriate angle function, restitution angle function, etc., were adopted for aluminium. However, after validation, all of the simulations were performed for steel pipe material.

All of the grids were generated using GAMBIT 2.3.16 (2006). Numerical simulations were carried out for different elbows and plugged tees with internal diameters of $0.0254,0.1,0.2,0.4$ and $0.6 \mathrm{~m}$. All of the elbows were considered as a standard elbow ( $\mathrm{r} / \mathrm{D}=1.5$ ), and the ratio of plugged lengths to the diameter of the tee (L/D) was 1.5 in this study (see Figure 2).

Stochastic tracking was enabled, and the number of released particles at the inlet was adjusted accordingly. The mass flow rate of the particles at the inlet was changed according to the pipe diameter and flow velocity so that the particle concentration was constant for all simulations. The numerical simulations were carried out for four different particle diameters so that the common range of particle sizes found in the petroleum industry $(50-500 \mu \mathrm{m})$ were covered. Furthermore, the effect of flow velocity on the erosion ratio was investigated by performing the simulations for three different velocities $(15,30$ and $45 \mathrm{~m} / \mathrm{s})$. 


\section{RESULTS AND DISCUSSION}

\subsection{Validation of the Numerical Model}

Numerical simulation was first performed for a $0.0254 \mathrm{~m}$ diameter plugged tee and elbow with available experimental data. The experiments were carried out for an aluminium elbow and tee. The inlet velocity was $45.72 \mathrm{~m} / \mathrm{s}$, and the mass flow rate of the sand was $2.08 \times 10^{-4} \mathrm{~kg} / \mathrm{s}$ (Chen et al. 2006).

Experimental studies show that aluminium and steel behave differently in an erosive environment. Hence, appropriate impact angle function, restitution function and other coefficients were implemented in the erosion model according to the properties of aluminium (Oka et al. 1997).

Figure 3 shows the relative erosion rates in the aluminium elbow and tee. The sand particle diameter was $250 \mu \mathrm{m}$. To more clearly show the relative erosion between the elbow and tee, the erosion rates were normalised by the maximum erosion rate in the elbow. As seen in this figure, the predicted erosion rate in the plugged tee is less than that in the elbow. The area most vulnerable to erosion is the end region of the plugged tee, where the maximum erosion is around half of the predicted value for the elbow. In addition, the predicted erosion rate at the corner of the plugged tee is around ten times less than the maximum erosion rate in the elbow. In practice, the end region of the tee can be made thicker to increase its resistance in an erosive environment.

According to the available experimental data, the relative erosion rate at the end region and the corner of the tee are 0.496 and 0.118 , respectively (Chen et al. 2006). Figure 4 shows the relative erosion at the end of the plugged tee for different particle sizes as predicted by the CFD model and the experiment. As seen, the predicted relative erosion rates using the CFD model agree very well with those obtained in the experiment.

Due to the empirical nature of erosion models, quantification of erosion rate usually involves high uncertainties. Hence, in spite of the capability of these models in predicting the erosion pattern and hot spots the predicted erosion rates are not often close to the experimental values. For such conditions, despite the weakness of the models in quantifying the erosion rates, they can be used as a reliable tool for a comparative study of erosion rates in different geometries made by the same material. In fact the ratio of the erosion rates for two fittings made from the same material depends mainly on the flow-field and particle trajectories and the uncertainties in empirical constants such as particle shape and material properties will not affect the relative erosion rate between elbow and plugged tee (see Eq:14). A manifest of this point is observed in Figure. 4. The same numerical approach was applied for the obtained results of this study. Hence, the level of the accuracy of the results should be similar to those depicted in Figure. 4. Apart from this, using a relative erosion rather than erosion rate would be a better aid for comparative study of the performance of these fittings in an erosive environments.

\subsection{Numerical Results of Steel Fittings}

Numerical modelling was carried out for the steel plugged tees and elbows with different diameters ranging from 0.0254$0.6 \mathrm{~m}$. To investigate the effect of sand particle size, numerical simulations were performed for four different particle diameters of 50, 100, 300 and $500 \mu \mathrm{m}$. The influence of flow rate on relative erosion was studied by considering three different velocities of 15,30 and $45 \mathrm{~m} / \mathrm{s}$.

To compare the resistance of the plugged tee and elbow in a quantitative manner, the erosion rates in both geometries were normalised by maximum penetration rate in the elbow, which is referred to as relative erosion. The end and the corner regions of the tee are two critical locations at which the maximum penetration rate may occur. Hence, the effects of operating conditions on relative erosion in these critical regions are presented separately.

\subsubsection{Relative Erosion at the End of Plugged Tees}

Figure 5 shows the relative erosion at the end of the plugged tee. All numerical simulations shown in this figure were conducted for an internal velocity of $45 \mathrm{~m} / \mathrm{s}$. However, the sand particle size and pipe diameter varied within the previously mentioned common operating condition ranges.

As expected, due to the different behaviour of steel compared to aluminium, different relative erosion was observed at the end region of the plugged tee, which is mainly due to the difference in angle function of these two materials. According to this figure, for a $0.0254 \mathrm{~m}$ steel plugged tee and elbow, the relative erosion at the end region is around 0.2 , which is lower than that in an aluminium tee. The present numerical results revealed that for fittings with internal diameters of less than 0.2 
$\mathrm{m}$, almost all of the particles hit the end region of the tee. However, with further increases in pipe diameter, some of the incoming particles hit the corner of the tee without entering the plugged region. Due to the lower inertial force of small particles, more particles will follow the streamline of the flow field. Hence, more direct impacts are expected at the corner of the plugged tee. In fact, an increase in pipe diameter results in a decrease in the Stokes number of flow, thereby increasing the number of particles following the streamlines of flow. The obtained CFD results for an internal velocity of $45 \mathrm{~m} / \mathrm{s}$ indicate that large-diameter particles always hit the end region of the tee irrespective of the size of the fitting. However, as we increase the diameter of the pipe, the number of small particles that directly impact the corner, without colliding with the end region, increase. Moreover, as we increase the diameter of the pipe, the velocity of small particles within the plugged region of the tee dramatically decreases, which in turn significantly reduces the penetration rate. According to the present results for small particles, there exists a critical pipe diameter beyond which the relative erosion at the end region of the tee approaches zero. The predicted critical pipe diameters for sand particles with diameters of 50 and $100 \mu \mathrm{m}$ are 0.4 and $0.6 \mathrm{~m}$, respectively.

To investigate the effect of velocity on the relative erosion rate between the end region of the tee and elbow, numerical simulations were conducted for the same geometries and particle sizes, but the internal velocity was reduced to $30 \mathrm{~m} / \mathrm{s}$. Figure 6 shows the relative erosion rate in plugged tees and elbows at a constant velocity of $30 \mathrm{~m} / \mathrm{s}$. The figure shows that the overall trend of relative erosion for large particles is the same as the predicted trend for the higher velocity of $45 \mathrm{~m} / \mathrm{s}$. The numerical simulations indicate that a decrease in flow velocity results in an increase in the tendency of small particles to follow the flow streamlines. As a result, the critical pipe diameter beyond which there is no erosion at the end region decreases. Comparison of Figures 5 and 6 shows this fact with more clarity. From Figure 6, it can be seen that the critical pipe diameters for sand particles of 50 and $100 \mu \mathrm{m}$ are 0.2 and $0.4 \mathrm{~m}$, respectively.

The minimum flow velocity considered in this study was $15 \mathrm{~m} / \mathrm{s}$. Figure 7 shows the predicted relative erosion at the end region of the tee for this velocity. As expected, with a further decrease in the flow rate, the critical pipe diameter beyond which the relative erosion of small particles approaches zero decreases. However, for large-size particles, the relative erosion at the end region is almost independent of the pipe diameter. By comparing the predicted relative erosion of large particles at different velocities, it can be concluded that the relative erosion at the end region is almost independent of the flow rate.

Comparison of the impact velocities in the elbows and the end region of the plugged tees indicates that the impact velocity of particles at the end region of the tees is always less than that in the elbows. Furthermore, the impact angles of the majority of particles in the elbows are close to the critical angle at which maximum erosion occurs. However, in the plugged tee, the impact angle of the majority of particles in the first impingement with the end region is around $90^{\circ}$. Hence, a lower penetration rate is expected at the end region of plugged tees compared to that in the elbows. In practice, the end region of plugged tees can be made thicker to be even more robust in an erosive environment.

\subsubsection{Relative Erosion at the Corner of Plugged Tees}

Figure 8 illustrates the predicted relative erosion rate at the corner of plugged tees for a constant velocity of $45 \mathrm{~m} / \mathrm{s}$. From this figure, it is obvious that as we increase the pipe diameter, the relative erosion at the corner increases. The figure also shows the significant influence of particle size on the relative erosion at the corner. Of note, as we increase the size of the pipe, the erosion rate in the elbow decreases, whereas the penetration rate at the corner of the tee increases. Therefore, the ratio of erosion at the corner of the tee to that in the elbow increases. An analogous behaviour is observed when we decrease the size of the particles. As seen in this figure, the erosion rate at the corner of the plugged tee may become comparable or even higher than that in the elbow for certain conditions, which contradicts the common belief about the advantage of tees over elbows in an erosive environment.

Figure 9 depicts the relative erosion at the corner of plugged tees at the lower velocity of $30 \mathrm{~m} / \mathrm{s}$. By comparing between Figures 8 and 9, it is concluded that a decrease in the flow rate results in a higher relative erosion at the corner of the tee. Figure 10 shows the predicted relative erosion for the flow velocity of $15 \mathrm{~m} / \mathrm{s}$. As can be seen, the trend of the predicted relative erosion for different pipe diameters and sand particle sizes is very similar to the obtained trend for higher velocities, except for very fine particles of $50 \mu \mathrm{m}$, for which a further increase in pipe diameter from 0.4 to $0.6 \mathrm{~m}$ results in a decrease in relative erosion at the corner. This reduction may be attributed to the fact that with further increases in pipe diameter, the impact angle at the corner of plugged tees significantly decreases. Figure 11 shows the pattern of relative erosion for these two cases as obtained by the CFD model. As depicted, the erosion rate in the corner of the plugged tee may become significantly higher than that in the elbow. 
The effect of particle size on erosion patterns is illustrated in Figure 12. The figures depict the erosion patterns at a constant velocity of $45 \mathrm{~m} / \mathrm{s}$ and pipe diameter of $0.4 \mathrm{~m}$. As the images show, large particles cause severe wear at the end region of the plugged tee that is significantly less than the penetration rate in the elbow. However, small particles penetrate the corner region of the tee, and the erosion rate is comparable with that in the elbow.

As mentioned above, for a constant pipe diameter and flow rate, small-diameter particles cause more severe erosion at the corner of plugged tees. Sand particle sizes, which typically range from 50-700 microns, depend on the geology of the reservoir. However, with the use of sand exclusion measures, large particles are usually excluded. In such conditions and for largediameter piping systems, standard elbows are more resistant than plugged tees to erosion.

The viscosity of the carrier fluid may also change the erosion pattern significantly. By increasing the viscosity of the continuous phase, the particle relaxation time decreases, which in turn increases the tendency of particles to follow the flow streamlines and hit the corner of the plugged tee even at comparatively higher velocities, smaller pipe diameters and larger sand particle sizes. As a result, the severity of erosion at the corner of the tee increases. In many applications such as subsea piping systems, the flow field is under conditions of high pressure and high temperature for which the viscosity of the carrier fluid is higher than that in normal conditions (Shames 2003; Bai and Bai 2012). Therefore, the severity of erosion at the corner of plugged tees may increase further. It is also worth mentioning that due to the high viscosity and density of carrier fluid in liquid/solid flows, most of particles follow the streamlines of flow. As observed in the present study, this phenomenon substantially increases the erosion rate at the corner of plugged tee. Previous studies also show that the erosion ratio between plugged tee and elbow in liquid-solid flow is higher than that in gas-solid flow ( Chen et al. 2006; Azimian and Bart 2014). Hence, the results of this study cannot be used for liquid/sand flows.

Numerical results of the turbulent flow-field indicated that the pressure drop in plugged-tee is always higher than that in elbow. Comparative study of the pressure drop for all the conditions considered in this study revealed that the pressure drop in plugged tee is around 3-4 times higher than that in elbow. Although reducing the pressure drop is an important design factor, avoiding structure failure due to the erosion is a primary concern that cannot be ignored. However, for working conditions in which the erosion rate in plugged tee may become comparable or even higher than that in elbow, using elbow is suggested.

\subsection{Numerical Simulation of Erosion in Subsea Jumpers}

To examine the effectiveness of the results of this study in designing complex piping systems, numerical modelling of erosion in two rigid jumpers outfitted with standard elbows and plugged tees was conducted. With the exception of the type of fittings, both jumpers had the same dimensions (internal diameter of $0.4 \mathrm{~m}$ ). Figure 13 shows the schematic of one of the jumpers. The velocity of flow was $15 \mathrm{~m} / \mathrm{s}$, and sand particles 100 microns in size were introduced at the inlet. According to the obtained results shown in Figures 7 and 10, for a piping system with an internal diameter of $0.4 \mathrm{~m}$ and the aforementioned flow condition, the maximum erosion of the plugged tee should be observed at its corner, and the magnitude should be 0.48 of the maximum penetration rate in the elbow. As shown in Figure 14, numerical modelling of the erosion in jumpers also indicates that the maximum penetration point in a jumper outfitted with plugged tees is located at the corner of the tees. However, the magnitude of the predicted relative erosion is 0.57 , which is slightly higher than the expected value from Figure 10. The observed discrepancy between these two values might be attributed to the fact that the distances between fittings in these jumpers are comparatively small so that the particles cannot obtain an initial uniform distribution. Although the distribution of particles at the inlet of the jumper is uniform, with the exception of the first fitting, the others are facing a nonuniform distribution of particles at the inlet. As a result, the penetration rate may differ from the ideal condition in which the distribution of particles at the inlet is uniform. These results reveals the necessity of retaining a minimum pipe span between fittings so that the particulate flow can retrieve its initial distribution. Additional studies will be required to determine the minimum allowable distance between fittings in a complex piping system.

\section{CONCLUSION}

The objective of the presents study was to examine the accuracy of a common belief in industry that plugged tees are more resistant to erosion than standard elbows in erosive environments. To this end, a comprehensive numerical simulation of erosion was performed for both fittings in varying geometrical conditions ranging from 0.0254-0.6 m diameter carbon steel 
pipes (AISI 4130) transmitting multiphase gas/sand flows. Furthermore, the effects of internal flow velocity and sand particle size on the relative erosion between plugged tees and elbows were also investigated.

The relative severity of erosion between the plugged tees and elbows was found to be influenced by all three of these parameters. According to the present numerical results, for small-diameter pipes, the plugged tee shows more resistance to erosion. However, as the diameter of the fittings increases, the resulting erosion in the plugged tees become comparable to or even more severe than that in the standard elbows.

Numerical investigation of the effects of particle diameter also showed that as the particle diameter decreases, the relative erosion at the corner of the plugged tees increases. Further, the numerical results regarding the effect of flow velocity indicate that a decrease in flow rate results in an increase in relative erosion at the corner of the plugged tees.

Finally, the numerical model was used to predict the erosion rate in two subsea jumpers outfitted with standard elbows and plugged tees. The obtained results of erosion in the jumper models were found to be in good agreement with the predicted relative erosion demonstrated in this study. Hence, the results of this study may be used as a guideline in selecting an appropriate fitting type for the different working conditions investigated in this study.

\section{ACKNOWLEDGEMENTS}

This work was supported by a 2-Year Research Grant of Pusan National University

\section{REFERENCES}

Abdolkarimi V, Mohammadikhah R. 2013. CFD modeling of particulates erosive effect on a commercial scale pipeline bend. ISRN Chemical Engineering. 2013:1-10.

Ahlert K. 1994. Effects of particle impingement angle and surface wetting on solid particle erosion of AISI 1018 steel. M.S. Thesis, University of Tulsa, OK.

Azimian M, Bart HJ. 2014. Investigation of hydro abrasion in slurry pipeline elbows and t-junctions. Journal of Energy and Power Engineering. 8:65-78.

Bai Y, Bai Q. 2012. Subsea Engineering Handbook. Gulf Professional Publishing.

Barton NA. 2003. Erosion in elbows in hydrocarbon production system: A review document. Research report Scottish Enterprise Technology Park, East Kilbrede (Research Report 115).

Bourgoyne AT. 1989. Experimental study of erosion in diverter systems due to sand production. SPE/IADC-18716, Louisiana.

Brown GJ. 2002. Erosion prediction in slurry pipeline tee-junctions. Applied Mathematical Modelling. 26(2):155-170.

Chen X. McLaury BS, Shirazi SA. 2004. Application and experimental validation of a computational fluid dynamics (CFD)based erosion prediction model in elbows and plugged tees. Journal of Computer and Fluids. 33:1251-1272.

Chen X, McLaury BS, Shirazi SA. 2006. Numerical and experimental investigation of the relative erosion severity between plugged tees and elbows in dilute gas/solid two-phase flow. Wear. 261:715-729.

Edwards KE, McLaury BS, Shirazi SA. 2001. Modeling solid particle erosion in elbows and plugged tees. Journal of Energy Resource Technology. 123:277-284.

Fluent User's Guide, Release 14, Ansys Inc., USA, 2011.

Forder A, Thew M, Harrison D. 1998. Numerical investigation of solid particle erosion experienced within oilfield control valves. Wear. 216(2):184-193.

Gambit User's Guide, Release 2. 3. 16, Ansys Inc., USA, 2006.

Grant G, Tabakoff W. 1975. Erosion prediction in turbomachinery resulting from environmental solid particles. Journal of Aircraft. 15(5): 471-478.

Lee SE, Paik JK., Ha YC, Kim BJ, Seo JK. 2014. An efficient design methodology for subsea manifold piping systems based on parametric studies. Ocean Engineering, 84:273-282. 
McLaury BS. 1996. Predicting solid particle erosion resulting from turbulent fluctuation in oilfield geometries. PhD Dissertation, University of Tulsa, OK.

Morsi S, Alexander A. 1972. An investigation of particle trajectories in two-phase flow systems, Journal of Fluid Mechanics. 55(2):193-208.

Njobuenwu OD, Fairweather M. 2012. Modelling of pipe bend erosion by dilute particle suspensions. Computers and Chemical Engineering. 42:235-247.

Oka YI, Ohnogi H, Hosokowa T, Matsumura M. 1997. The impact angle dependence of erosion damage caused by solid particle impact. Wear. 203-204:573-579.

Parsi M, Najmi K, Najafifard F, Hassani S, McLaury BS, Shirazi SA. 2014. A comprehensive review of solid particle erosion modeling for oil and gas wells and pipeline applications, Journal of Natural Gas Science and Engineering. 21:850-873.

Parslow G, Stephenson D, Strutt J, Tetlow S. 1997. Erosion damage mapping in a standard 90 degree take-off subsea Christmas tree assembly. Journal of the Society for Underwater Technology. 22:95-101.

Pereira GC, Souza FJD, Martins DADM. 2014. Numerical prediction of the erosion due to particles in elbows. Wear. 261:105-117.

Safaei MR, Mahian O, Garoosi F, Hooman K, Karimpour A, Kazi SN, Gharehkhani S. 2014. Investigation of micro- and nanosized particle erosion in a $90^{\circ}$ pipe bend using a two-phase discrete phase model. The Scientific World Journal. 2014:1-12.

Salama MM. 2000a. Sand production management. Journal of Energy Resourced Technology. 122:29-33.

Salama MM. 2000b. An alternative to API 14E erosional velocity limits for sand-laden fluids. Journal of Energy Resources Technology. 122:71-77.

Salama MM. 2000c. Influence of Sand Production on Design and Operations of Piping Systems. CORROSION. Orlando, Florida, 26-31 March.

Shames IH. 2003. Mechanics of fluids. McGraw-Hill.

Sommerfeld M, Huber N. 1999. Experimental analysis and modelling of particle-wall collisions. International Journal of Multiphase Flow. 25(6-7): 1457-1489.

Wang J, Shirazi SA. 2003. A CFD based correlation for erosion factor for long-radius elbows and bends. Journal of Energy Resource Technology. 125:26-34.

Zhang Y, Reuterfors EP, McLaury BS, Shirazi SA, Rybicki EF. 2007. Comparison of computed and measured particle velocities and erosion in water and air flows. Wear. 263:330-338. 
Table 1. Empirical constants used in the erosion model.

\begin{tabular}{ccc}
\hline Constant & Steel & Aluminium \\
\hline$\theta_{0}$ & $\pi / 12$ & $\pi / 18$ \\
\hline $\mathrm{n}$ & 2.41 & 2.41 \\
\hline $\mathrm{A}$ & $2.17 \times 10^{-7} \times B H^{-0.59}$ & $0.388 \times 10^{-7}$ \\
\hline$K_{1}$ & -0.334 & -34.79 \\
\hline$K_{2}$ & 0.179 & 12.3 \\
\hline$K_{3}$ & 0.01239 & 0.147 \\
\hline$K_{4}$ & 1 & 5.205 \\
\hline$K_{5}$ & -0.01192 & -0.745 \\
\hline$K_{6}$ & 0.02167 & 1
\end{tabular}




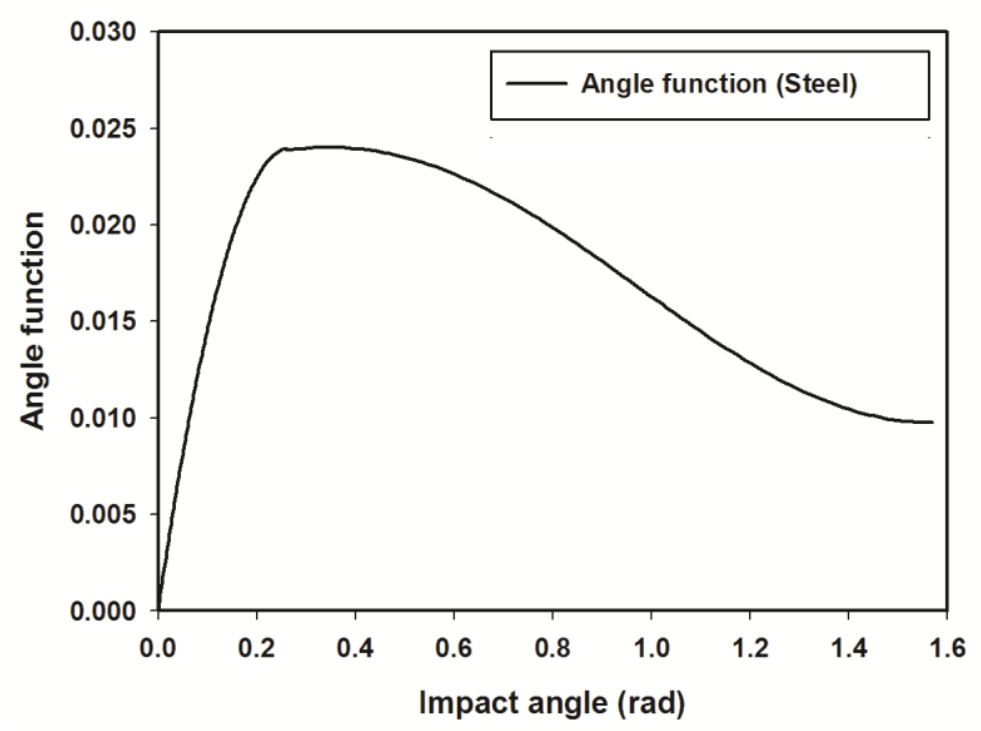

Figure 1. Angle function of steel used in this study 


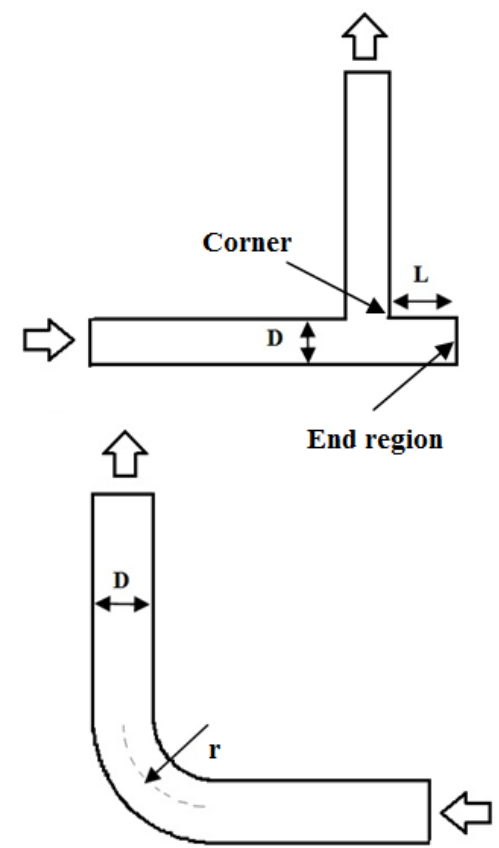

Figure 2. Schematic diagram of an elbow and plugged tee. 
$=$ 


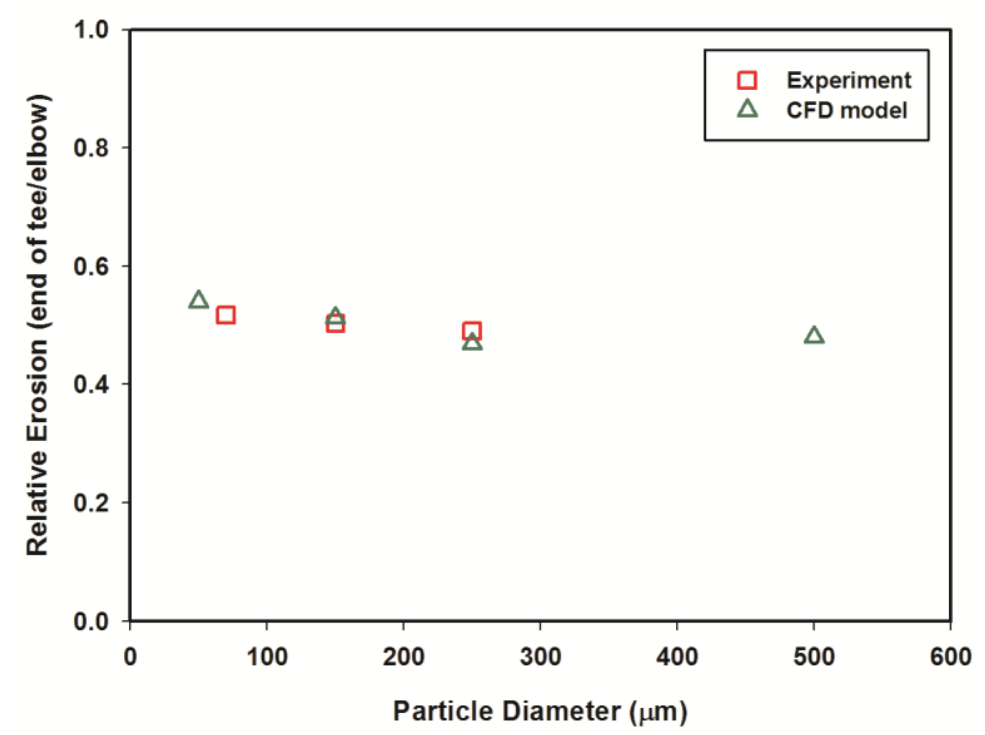

Figure 4. Predicted relative erosion between an aluminium plugged tee and elbow with internal diameter of $0.0254 \mathrm{~m}$. 


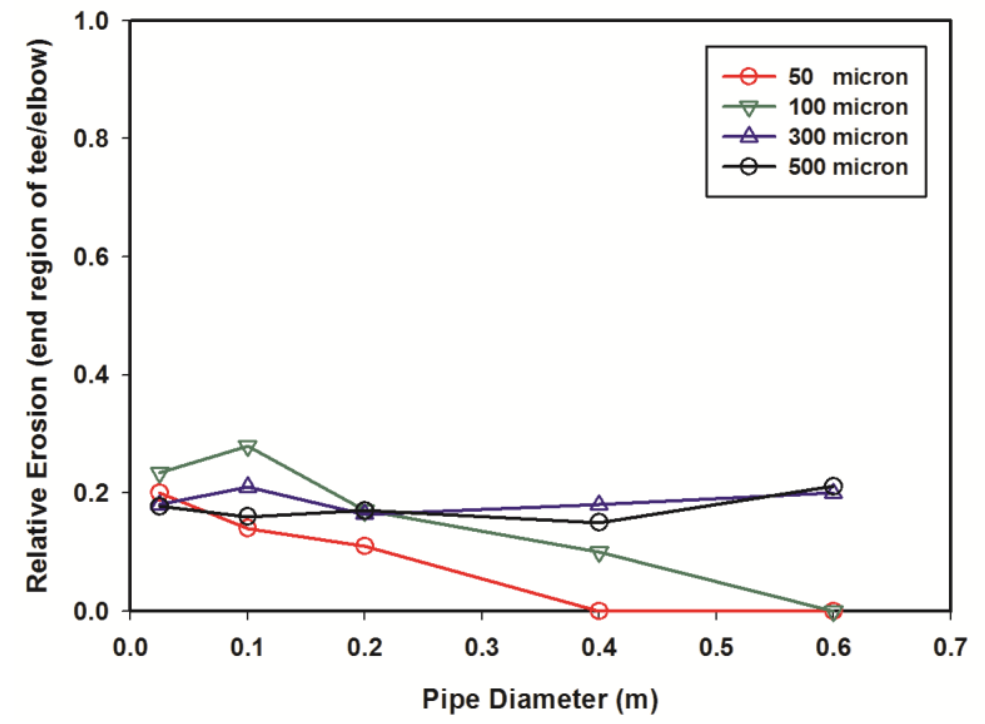

Figure 5. Predicted relative erosion at the end region of plugged tees at a velocity of $45 \mathrm{~m} / \mathrm{s}$. 


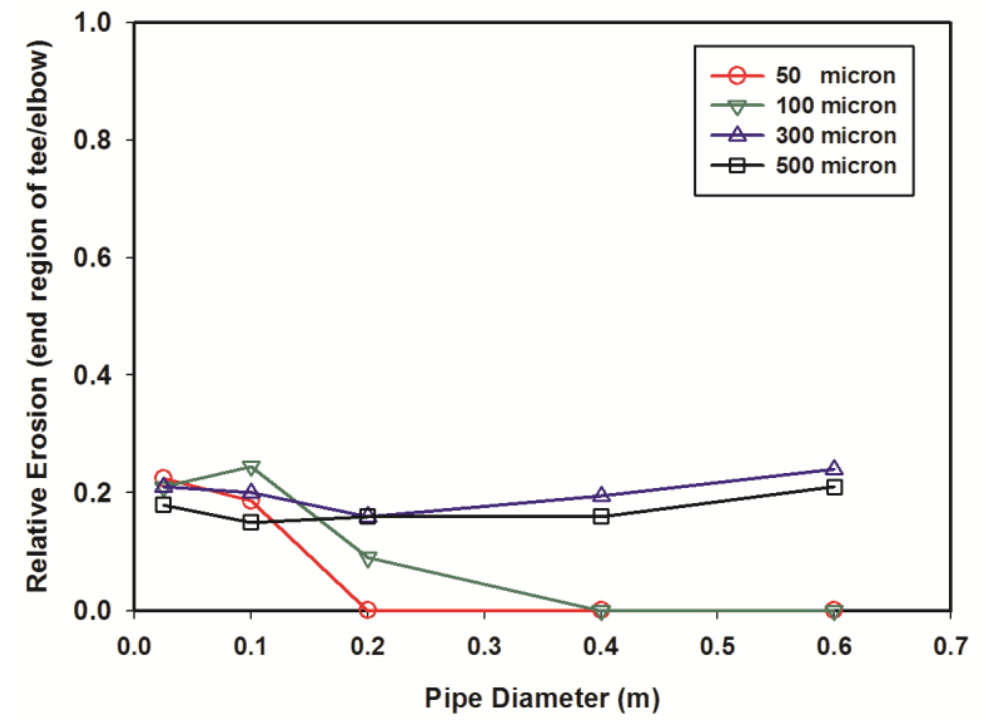

Figure 6. Predicted relative erosion at the end region of plugged tees at a velocity of $30 \mathrm{~m} / \mathrm{s}$. 


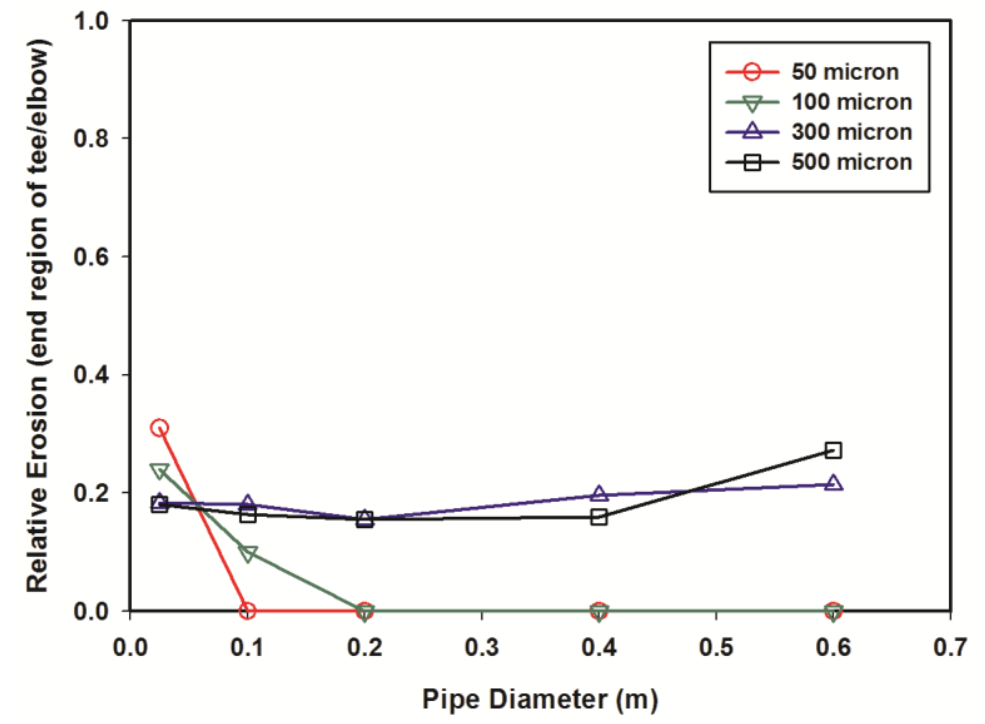

Figure 7. Predicted relative erosion at the end region of plugged tees at a velocity of $15 \mathrm{~m} / \mathrm{s}$. 


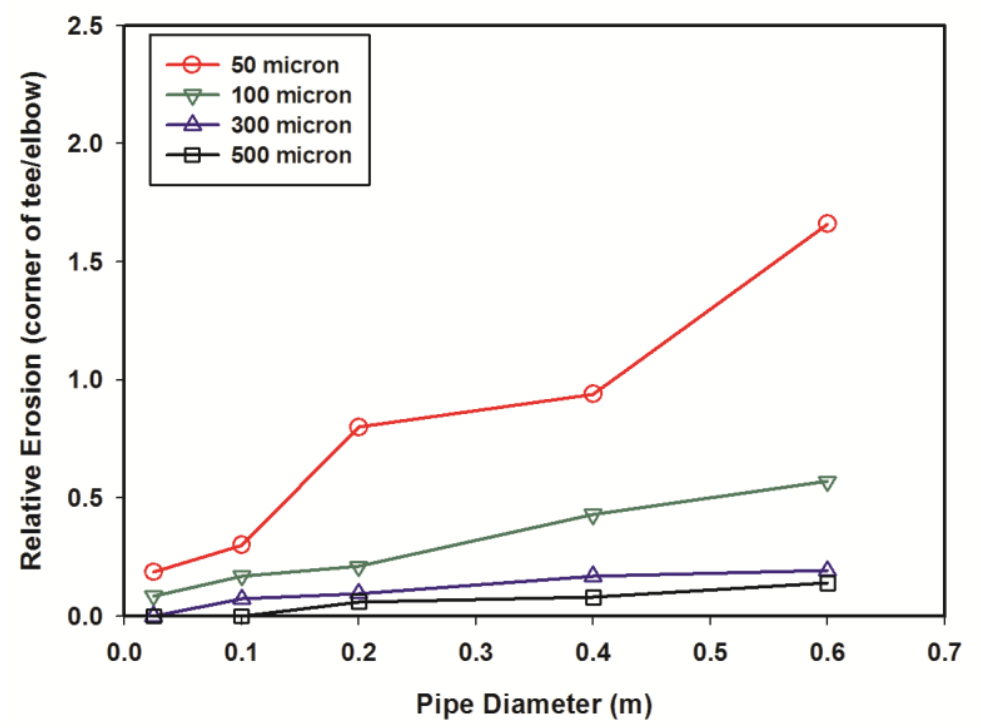

Figure 8. Predicted relative erosion at the corner of plugged tees at a velocity of $45 \mathrm{~m} / \mathrm{s}$. 


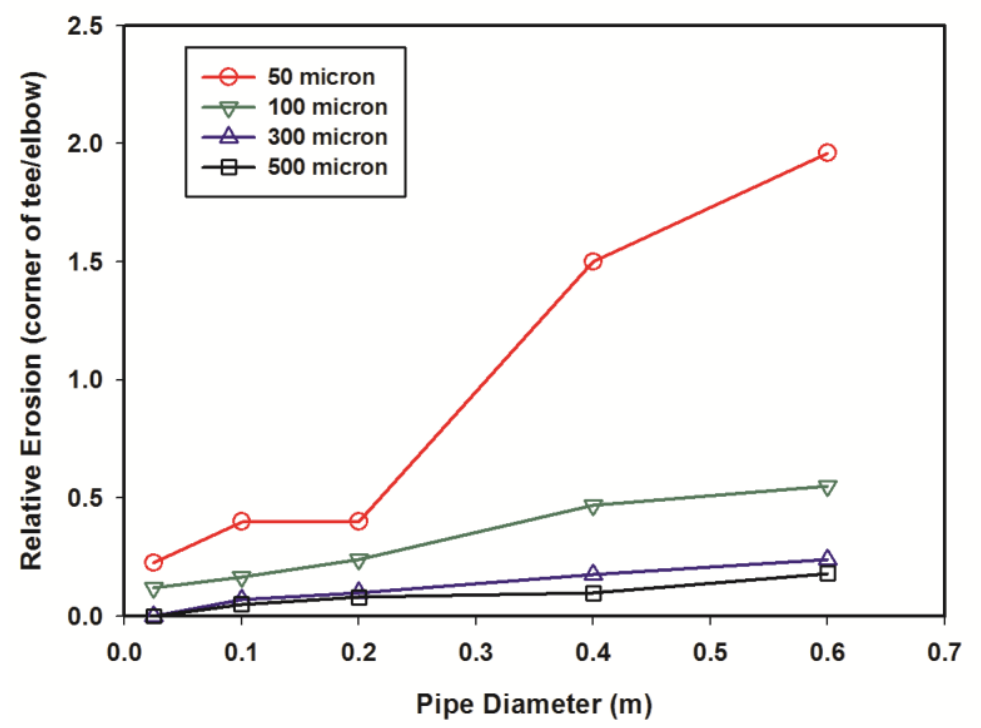

Figure 9. Predicted relative erosion at the corner of plugged tees at a velocity of $30 \mathrm{~m} / \mathrm{s}$. 


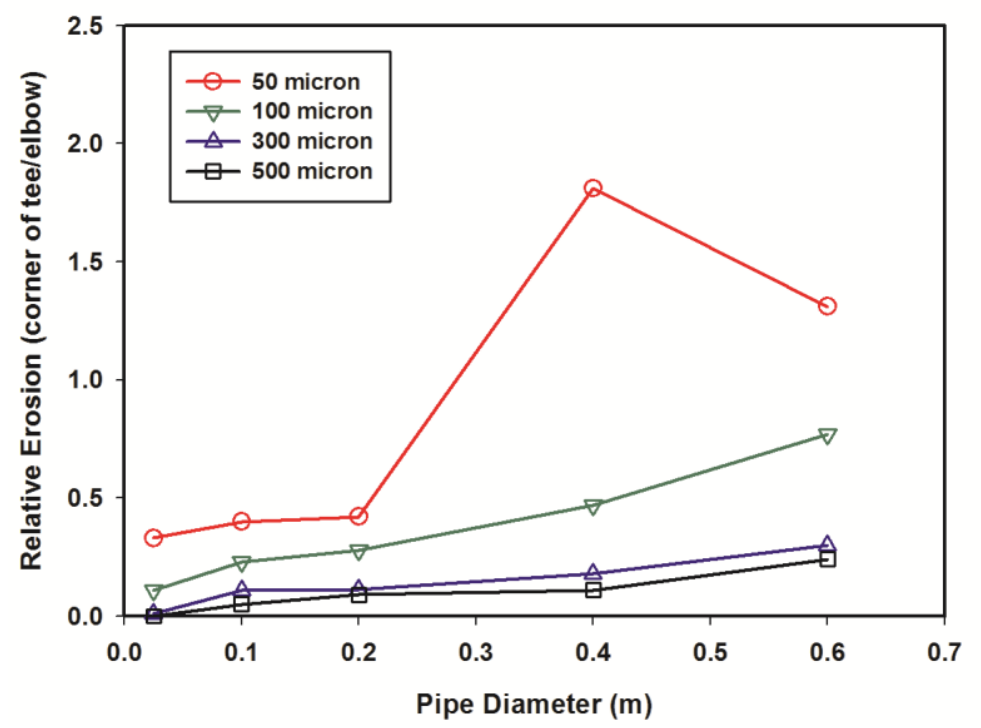

Figure 10. Predicted relative erosion at the corner of plugged tees at a velocity of $15 \mathrm{~m} / \mathrm{s}$. 

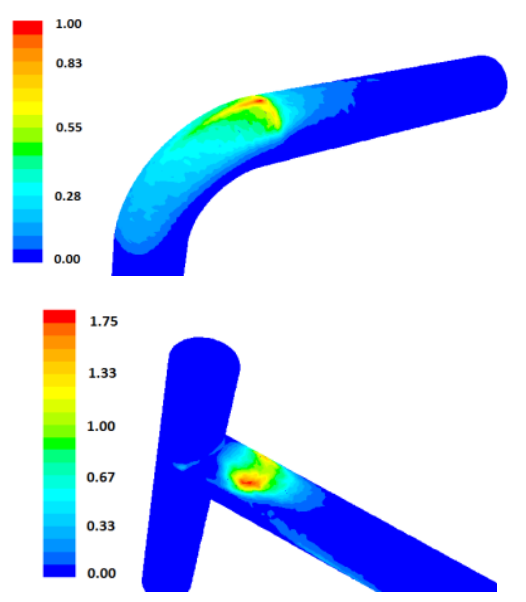

a)
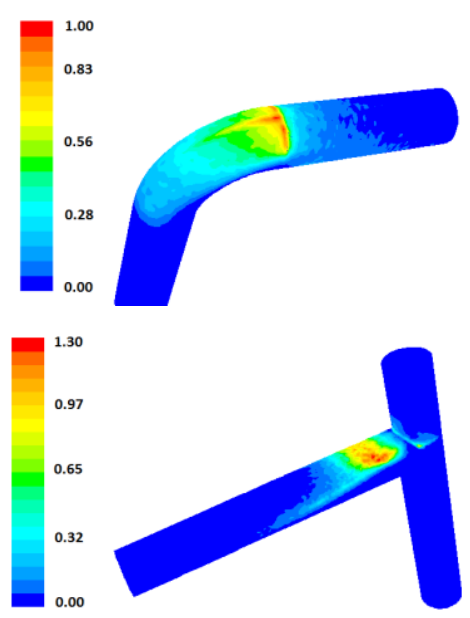

b)

Figure 11. The effect of pipe diameter on predicted relative erosion patterns. a) Flow velocity $=15 \mathrm{~m} / \mathrm{s}$, particle size $=50$ $\mu \mathrm{m}$ and pipe diameter $=0.4 \mathrm{~m}$. b) Flow velocity $=15 \mathrm{~m} / \mathrm{s}$, particle size $=50 \mu \mathrm{m}$ and pipe diameter $=0.6 \mathrm{~m}$. 


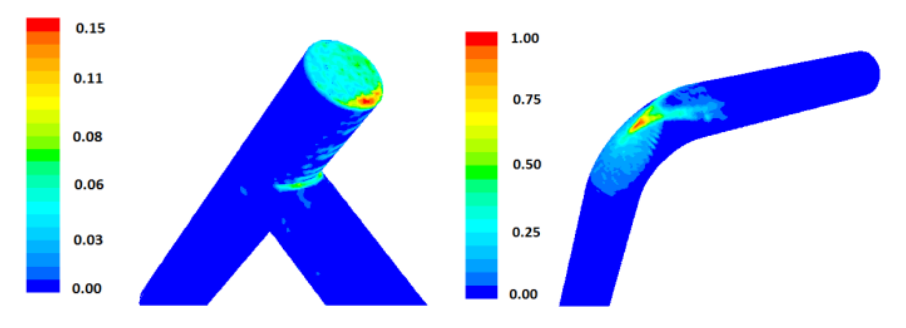

a)

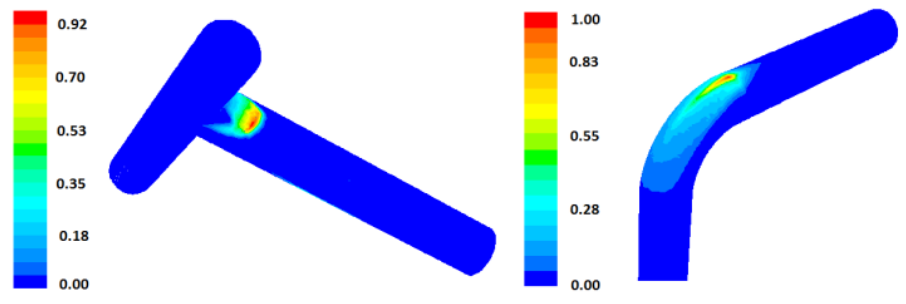

b)

Figure 12. The effect of particle size on erosion patterns in tees and elbows. a) Internal velocity $=45 \mathrm{~m} / \mathrm{s}$, pipe diameter $=$ $0.4 \mathrm{~m}$ and particle size $=500 \mu \mathrm{m}$. b) Internal velocity $=45 \mathrm{~m} / \mathrm{s}$, pipe diameter $=0.4 \mathrm{~m}$ and particle size $=50 \mu \mathrm{m}$. 


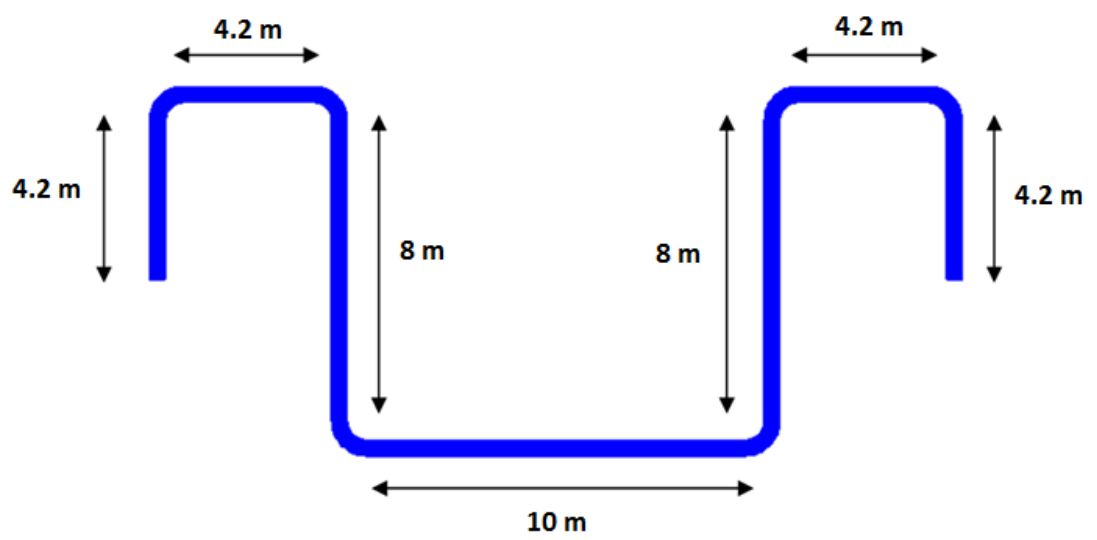

Figure 13. Schematic of the geometry of the subsea jumper. 


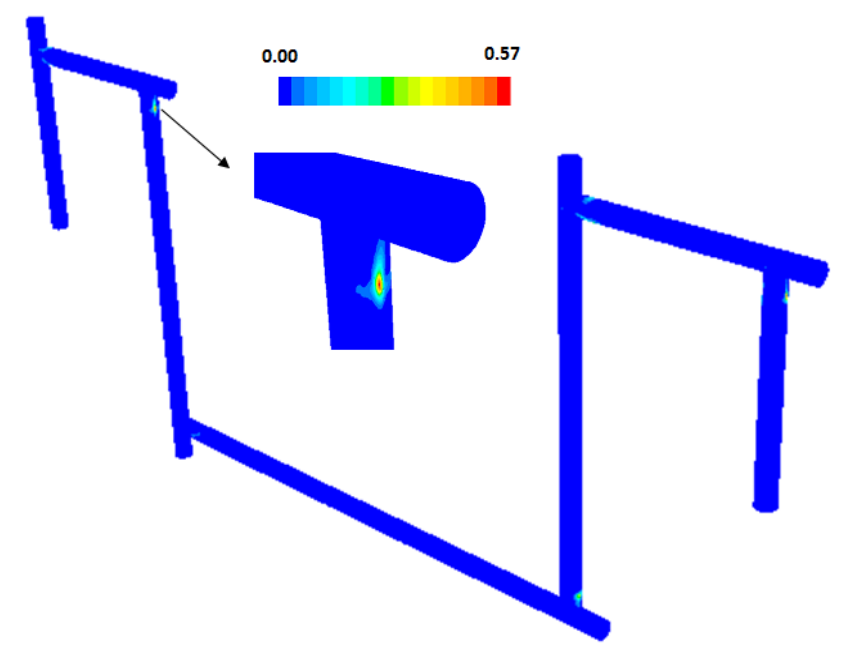

a)

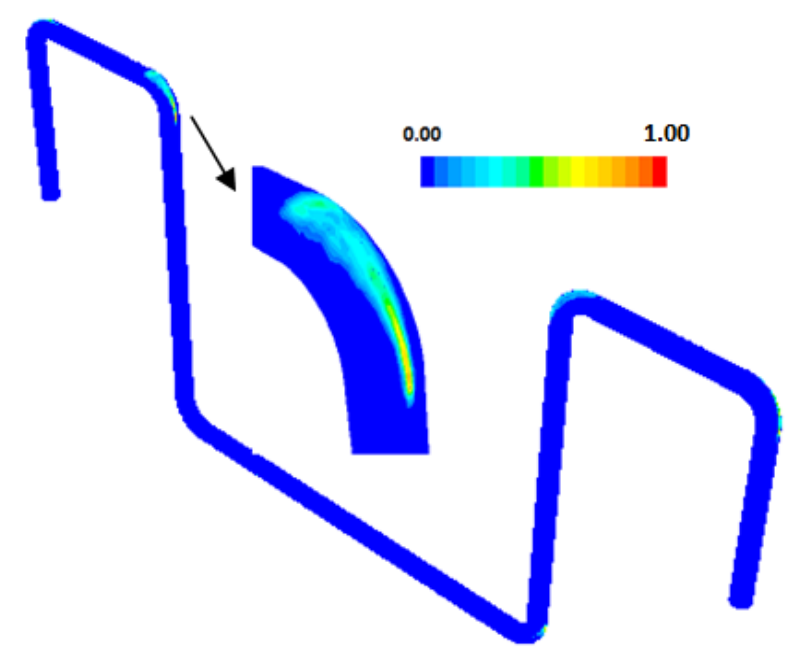

b)

Figure 14. Erosion patterns in sub-sea jumpers as obtained by the present CFD model. a) Subsea jumper outfitted with plugged tees. b) Sub-sea jumper outfitted with standard elbows. 